\title{
A ANARQUIA IMEMORIAL DO MUNDO - LEVINAS E A
ÉTICA DA SUBSTITUIÇÃO
}

André Brayner de Farias*

RESUMO - O tema da substituição é o coração da filosofia levinasiana. O desejo do infinito, a questão que move o pensamento, expressa-se na fórmula: tero-outro-em-sua-pele. Segundo Levinas é isso o que explica o fato de sermos tão numerosos no mundo. A substituição é a sustentação do mundo. Mas não significa isso uma idéia de fundamento. A metafísica levinasiana aborda o ser como questão que excede o princípio de uma fundamentação filosófica ou condição de possibilidade. O ser em questão é anterior ao princípio como o outro-em-sua-pele não é uma condição subjetiva, mas a incondição do pensamento, o desde sempre da responsabilidade: anarquia imemorial do tempo e do mundo.

PALAVRAS-CHAVE - Ética. Substituição. Subjetividade. Anarquia imemorial. Desejo do infinito.
ABSTRACT - The notion of substitution is at the heart of Levinas's philosophy. The desire of the infinite - which drives the way we think - is expressed in the formula: having-the-other-in-one's-skin. According to Levinas, that is the reason why there are many of us in the world. The substitution sustains the world, but such idea cannot be seen as groundwork. Considering Levinas's metaphysics, Being is an issue that exceeds the principles of philosophical groundwork or condition of possibility. Being precedes the beginning in the same way as the-other-in-one's-skin formula is not a subjective condition. It is the uncondition of thinking since responsibility has always existed: world's time immemorial anarchy.

KEY WORDS - Ethics. Substitution. Subjectivity. Immemorial anarchy. Desire of the infinite.

"A questão é o desejo do pensamento."

(MAURICE BlANCHOT, A conversa infinita)

\section{A questão além do ser - outramente}

Dizer a subjetividade pela substituição ao outro significa se separar da longa tradição ontológica do pensamento filosófico, cuja linguagem consiste

* Doutor em Filosofia pela PUCRS/Université de Toulouse, Professor do Departamento de Filosofia da Universidade de Caxias do Sul.

\begin{tabular}{|l|l|l|l|l|l|} 
VERITAS & Porto Alegre & v. 53 & n. 2 & abr./jun. 2008 & p. $18-34$
\end{tabular}


em atender à expectativa de um ouvido habituado à inteligibilidade dos nomes, quando estes prometem, pela cópula do verbo ser no presente do indicativo, a perfeita adequação da substância a ela mesma. No caso da questão levinasiana - ter-o-outro-em-sua-pele - o Outro ocupa o lugar que a ontologia, para não irritar nossos ouvidos, reservara ao Mesmo. É evidente a ambigüidade desse modo de linguagem. Mas ela, a ambigüidade, só desautoriza no quadro estreito da significação dos nomes, na dinastia da substantivação. A ambigüidade é quando a palavra "é" não decide o pensamento, quando a questão ressoa sempre mais alto que a hipocrisia da resposta. E como diz Blanchot, "a resposta é a desgraça da questão"1. Aqui a ambigüidade é bem quista. A linguagem, destinada a dizer além dos nomes, na ausência do que seja, é o equívoco silencioso do pensamento. O outro-no-mesmo é a infinitude da questão.

A subjetividade se produz no entretempo diacrônico da recorrência em que o Mesmo, a caminho de si - a caminho do Si mesmo como promessa de uma substância onde a identidade subjetiva alcançaria seu lugar na coincidência do Nome, ser-em-si, ser-para-si - já se encontra no movimento sem fim da responsabilidade. É nessa recorrência, movimento de exteriorização, transcendência da provocação produzida pela idéia do infinito em mim, que escutamos a ressonância da substituição, movimento ou modalidade do outramente que ser. A recorrência é a idéia do infinito em mim. Não é possível pensar aí senão a verbalidade pura, a inquietação do não-lugar - utopia do humano. A utopia não é uma realidade sem lugar, mas a realidade do não-lugar. $A$ subjetividade é a anarquia imemorial do mundo.

\section{Infinito}

Pensar o sujeito como ato de consciência e liberdade é pensar atributos de um conceito de $\mathrm{Eu}$, atividade que pressupõe uma subjetividade já em produção. A subjetividade não é o conceito de Eu, mas o exílio infinito de si. A ontologia como linguagem e filosofia primeira é o ser retornado a si mesmo e identificado ao seu nome, o saber e o conhecimento como horizonte de toda espiritualidade possível. Quando dizemos que a "subjetividade é a substituição ao outro", estamos traindo a expectativa concentrada no verbo conjugado, como se disséssemos que "A não coincide com A". Sustentamos, então, que a filosofia não é apenas o horizonte do saber - numa tradição que, aliás, remonta a Kant, mas que também dela se separa ${ }^{2}$ - nem a ontologia o único dizer possível. Quando se trata de pensar a subjetividade ou, o que dá no mesmo, de investigar a remota origem do sentido, cujos fragmentos à guisa de vestígio incomodam a inteireza do nome e seu desejo

1 BLANCHOT, M. A conversa infinita - a palavra plural. São Paulo: Escuta, 2001. p. 43.

2 Ver CHALIER, C. Pour une morale au-delà du savoir - Kant et Levinas. Paris: Albin Michel, 1998. 
de se manter incólume na função de dar sentido e produzir pensamento, entramos num território de racionalidade e linguagem diferentes, o campo da ética como significação primeira. A filosofia da subjetividade é a exceção da linguagem ontológica na anterioridade anárquica que implica a estrutura do Outro-no-Mesmo - substituição.

O desafio está em trazer ao pensamento, povoado de expectativa identificante, algo que não alcança o estatuto de princípio que a identidade exige. Mas o pensamento é o movimento do pensar. É possível, então, mobilizar a expectativa do pensamento, imaginá-lo, por exemplo, não como uma instância fixa onde os problemas tendem a uma solução e onde o único movimento possível assemelha-se a uma espécie de purificação de conteúdos, polimento da matéria caótica da questão em vista de uma forma adequada à inteligência. Como se de uma domesticação se tratasse. Pensar se reduziria, então, a este movimento de domínio da realidade exterior - matéria caótica e anárquica da questão - e não vamos mais nos perguntar sobre a obviedade dessa tendência de posse, onde toda relação com a exterioridade já está de saída comprometida?

Na filosofia que nos é transmitida, o sentido que não se refere àquilo que se instala na positividade da terra firme sob a abóbada do céu passa por puramente subjetivo, por sonho de uma consciência infeliz. A questão, a Busca e o Desejo são privações da resposta, da posse, do gozo. Não se pergunta se a questão paradoxalmente desigual a si mesma não pensa além, se a questão, em lugar de nela carregar apenas o vazio da necessidade, não é a própria modalidade da relação com o outro, com aquele que não pode ser abarcado, com o Infinito. Com Deus. A questão, antes de se pôr no mundo e de se satisfazer com respostas, seria, pelo pedido ou pela oração que exprime - pela admiração em que ela se abre - relação-a-Deus, a insônia originária do pensar ${ }^{3}$.

Antes mesmo de discutir o sentido dessa matéria bruta da questão, trata-se de pensar que relação estamos dispostos a produzir entre filosofia e questão. Sem dúvida que caímos num debate sobre a idéia mesma da filosofia: que racionalidade merece, nessa idéia, um lugar de operação? Produzir filosofia como lugar de atualização constante da questão não significa transformar o pensamento em caos, mas manter-se num nível de operação racional onde o conceito não repousa tranqüilo como função de princípio de inteligibilidade, manter-se num nível de consciência em que conceituar a realidade é comprometer-se com o privilégio da questão, "insônia originária do pensar" onde o ídolo não encontra lugar para se alojar. Não significa isto pensar a filosofia como abertura criativa da realidade?

A questão não seria uma modificação, nem uma modalidade, nem uma modalização da apophansis, como a dúvida ou a consciência do provável ou

3 LEVINAS, E. De Deus que vem à idéia. Petrópolis: Vozes, 2001. p. 163. Abreviaturas das obras de Levinas utilizadas aqui: De Deus... DVI; Autrement qu'être ou au-delà de l'essence...AE; Quatro leituras talmúdicas...OLT; Au-delà du verset...ADV. A partir de agora valem essas abreviaturas. 
do possível. Ela é original. Ela é exatamente a figura que toma - ou o nó em que se tece - a desproporção da relação - sem esta figura impossível - do finito ao infinito, o "no" do "infinito no finito", que é também o fora mais exterior que toda exterioridade ou a transcendência ou a duração infinita que não chega nem vai a termo. Não é a este pensamento - diferente daquele que - consciência intencional quer à sua medida o correlato, o repouso e a identidade do positivo astronômico - que se refere Blanchot quando diz, paradoxalmente: "Nós pressentimos que o des-astre é o pensamento"? Inteligibilidade cujo insólito não se reduz a uma teologia negativa. A transcendência do Infinito não é recuperada nas proposições, sejam elas negativas ${ }^{4}$.

Não "pensamento da interrogação", como se a pergunta fosse a condição da partida, mas "pensamento como interrogação", força que atualiza o privilégio da questão. O extraordinário que há na fórmula "Infinito-no-finito", quando a relação mediante a qual o pensamento acontece já é a resposta à pro-vocação anárquica da questão. A subjetividade como abertura primeira, produção constante do pré-original, seria o antes da relação. A figura da relação deve, então, ser abandonada uma vez que já implica em 'estruturas' dispostas, e, dessa forma, deixamos que a substância caia novamente num estatuto de princípio. Uma filosofia que se produz como questão deve tornar inteligível a idéia do antes-do-princípio. Filosofar é pensar na diacronia do tempo, não para chegar ao conceito do tempo diacrônico, mas pensar tendo que dar conta do caráter essencial do tempo que é a diacronia. Não se trata de remeter o pensamento a um passado imemorial onde 'algo' teria acontecido e, portanto, teríamos que inventar não se sabe que forma não-representativa de dizer esse acontecimento. A diacronia é a imemorialidade que o ato da consciência (intencional) como produção do presente pressupõe. Todo ato assenta sobre uma passividade inatualizável. A subjetividade no ato da consciência já começou, não como resposta a uma questão de origem, mas como responsabilidade pelo infinito da questão.

\section{Criação}

A idéia de criação ex-nihilo não aparece por acaso no capítulo central de Autrement qu'être ${ }^{5}$. É disso que vai se tratar primeiro quando chegamos ao tema da substituição. Toda idéia de diacronia se esclarece aqui, até poderíamos dizer criação diacrônica. A criatura atende ao chamado da criação sem que a ordem tenha lhe alcançado, sem a sincronia de uma relação de causalidade. Significa isto a precedência da eleição com relação à ordem do ser. Passividade anárquica da criação onde a criatura, que ainda não recebeu uma definição ontológica, ou seja, desde antes de seu próprio

4 DVI. 163-164.

5 A respeito dessa idéia, a criação, ver CHALIER, C. La trace de l'infini - Emmanuel Levinas et la source hébraïque. Paris: Cerf, 2002. p. 21-42. 
princípio, já configura a ordem da responsabilidade, mesmo antes de receber as condições de responder pelos seus atos, antes de ser sujeito livre. "Talvez é aqui, nesta referência ao fundo de passividade an-árquica, onde o pensamento que nomeia a criatura difere do pensamento ontológico" ${ }^{6}$, pois, "na dimensão da criação, o sujeito, antes de ser definido pelo ser, é definido pela passividade da eleição"7. A racionalidade ontológica não poderia autorizar uma tal nomeação ex-nihilo, precisaria antes inventar a sincronia do tempo, domesticar a idéia de temporalidade, o que significaria não desautorizar uma autoridade que não foi recebida, ou seja, aceitar na consciência um ato de arbitrariedade cometido contra si próprio. A possibilidade de pensar o tempo como sincronia pressupõe o tempo como diacronia, que não autoriza em sua anterioridade a primazia de sua idéia de sincronia. A criatura designa uma instância estranha ou mesmo escandalosa para a razão do saber. $O$ dizer da subjetividade emperra 0 discurso do ser, exige uma estrutura de alcance argumentativo incompatível com a ontologia. "O problema é que a posição do sujeito é de-posição; incapaz de se identificar, o sujeito conserva em seu seio a estrutura da criatura: ele é 'o Outro-no-Mesmo'"8. Provavelmente o tema levinasiano da substituição seja o mais heterodoxo em relação ao discurso normal da filosofia, que não consegue compreender antes de identificar, quando identificar significa coincidir no ser. Talvez por isso mesmo a substituição seja o tema filosófico por excelência desse pensamento.

A criação ex-nihilo desenha uma lógica que inverte a ordem dos termos onde a razão ontológica opera sua dinâmica de argumentação. A possibilidade da criatura significa a precedência do fazer em relação ao entender, a primazia do acolhimento ético do outro em relação à tentação de compreendê-lo antes de mais nada e a fim de mensurar ou discernir razoavelmente sobre a possibilidade da acolhida. A criatura que responde antes de entender desenha a mesma lógica em que a ética se torna razoavelmente precedente à ontologia, e a responsabilidade, à liberdade.

\section{A confiança é a escuta}

Mas uma tal lógica diacrônica não parece mais tão estranha quando "pela confiança depositada naquele que fala prometemos obedecer e, desde logo, vamos escutar o que ele nos diz. Nada é menos paradoxal. Salvo o próprio nascimento da confiança anterior a qualquer análise" 9 . Que tipo de linguagem poderia nascer sem a precedência da confiança? Ou devemos pensar a confiança como uma modalidade do saber? Mas então a confiança

6 AE. 179.

7 PETROSINO, S.; ROLLAND, J. La vérité nomade - introduction à Emmanuel Lévinas. Paris: La découverte, 1984. p. 64.

8 Idem. p. 65.

9 OLT. 87. 
perderia seu sentido mais fundamental - a heteronomia da partilha, a transcendência prévia e sem mais - pois, uma vez derivada do saber, permaneceria condicionada, sem a gratuidade que constitui a própria verdade da confiança, estrutura por excelência de abertura, como o ato passivo de escutar. O saber é uma confiança solitária, permanência nos limites da mesmidade, crença no Eu como condição subjetiva de possibilidade. A confiança, esse nascimento anterior a qualquer análise, implica uma sujeição, um chamado a ser que é ter que responder antes de ser - estado de exceção da ontologia.

A lógica da criatura não parece bastante próxima da lógica que reproduzimos quando falamos com alguém? A comunicação não seria simplesmente possível se não pressupusesse a confiança (incondicional por natureza) naquele que fala, e incondicional não quer dizer sem compromisso com o saber, mas um modo de interpretar nossa relação aos outros para além das fronteiras do conhecimento. Quando falamos, confiamos primeiro e depois entendemos ou atendemos ao chamado da fala para então compreendê-la. A linguagem enquanto comunicação obedece, de uma certa forma, a mesma lógica da dificille liberté do povo de Israel que, para sair do cativeiro, teve que aceitar sua subordinação à lei da Torá. Se o sujeito fosse surdo ao chamado diacrônico da criação, surdo à eleição, o ser não teria a chance de nascer.

\section{Exílio}

O paradoxo - que para o espírito habituado a primeiro entender para depois falar torna quase impronunciável o logos da substituição, mas sem se dar conta que o entendimento pressupõe a escuta e, portanto, a passividade no fundo e como condição da atitude compreensiva - se revela no dizer dessa impossível coincidência do eu consigo mesmo, esse dizer de uma ausência do que seja. Obsessão na recorrência a si, a responsabilidade ao outro é a exibição mesma dessa situação paradoxal, luta interminável da linguagem. A recorrência é a aventura do exílio onde a subjetividade propriamente se revela: recorrência sem retorno porque sem chance de escolha. Não está ao alcance a decisão. O Outro é uma perseguição, uma obsessão que apaixona o sujeito provocando-o para uma aventura sem retorno, um exílio. Mas nesse exílio não estou alienado: o não retorno não significa a minha alienação, antes a concernência da responsabilidade. $O$ fato de que ninguém me pode substituir na responsabilidade e de que não está ao meu alcance a possibilidade da recusa significa a minha assinatura.

A responsabilidade na obsessão é uma responsabilidade do eu com relação ao que esse eu jamais quis, ou seja, com relação aos outros. Essa anarquia da recorrência a si, além do jogo normal da ação e da paixão onde se mantém onde é - a identidade do ser, aquém dos limites da identidade, esta passividade sofrida na proximidade por meio de uma alteridade em mim, esta passividade da recorrência a si que, no entanto, não é a alienação de 
uma identidade traída - que pode ela mais que a substituição de mim aos outros? Não alienação, no entanto, porque o Outro no Mesmo é minha substituição ao outro segundo a responsabilidade, pela qual, insubstituível, estou assinado. Pelo outro e para o outro, mas sem alienação: inspirado. Inspiração que é o psiquismo. Mas psiquismo que pode significar esta alteridade no mesmo sem alienação, ao modo de encarnação, como ser-nasua-pele, como ter-o-outro-na-sua-pele ${ }^{10}$.

É preciso supor uma multiplicidade de origem. $\mathrm{Na}$ intimidade mais secreta, mais atômica, por assim dizer, lá onde repousaria a unidade indivisível do sujeito, ressoa uma multiplicidade ${ }^{11}$. Minha assinatura reenvia a uma passividade que não se recupera no nível de visibilidade em que a assinatura remete à minha identidade subjetiva. O nível de visibilidade que o logos normalmente espera esconde o segredo dessa ancestralidade anárquica. Não como um ser por trás de uma aparência, mas como uma ordem anterior ao jogo do ser e do aparecer. Tal anterioridade se torna visível na própria manifestação dos problemas ontológicos, como o limite mesmo do ser. Nesse sentido, a alienação é exatamente o contrário do que seria o exílio do ser em si. Para o escândalo da lógica hegeliana, alienar o sujeito é encerrá-lo num conceito de subjetividade. A responsabilidade não é uma assinatura conceitual, mas a unicidade insubstituível do nó subjetivo, o momento em que o sujeito se ausenta de uma generalidade conceitual em que se alienaria no risco da indiferença. Um conceito de Eu não responde senão a uma coerência lógica e sistemática, totalidade sem infinito ético. Pela responsabilidade o sujeito se retira dessa lógica, se desaliena do Todo, convocado que está, desde sempre, à aventura sem retorno do infinito ético.

\section{A liberdade no outramente que ser}

Perseguição, obsessão, expiação: tudo parece indicar uma privação total da liberdade individual. Mas sobre que princípio assenta essa idéia de liberdade que se sente ameaçada? (A linguagem nos trai a todo momento e é preciso se defender). A idéia de liberdade - que tanto orgulha o pensamento moderno - se estabelece na base de um conceito substancialista ou formalista de sujeito, aliás, se estabelece como a base sólida desse conceito. A subjetividade transcendental de Kant é talvez o exemplo mais próprio. Mas aqui o sujeito é perseguido antes de seu princípio, ou seja, não se trata ainda de uma substância que merecesse ser objeto de perseguição implacável. Tal idéia de perseguição tornaria impossível a livre responsabilidade. A responsabilidade não é uma liberdade de escolha. Ao perseguir a tendência que o sujeito tem de retornar a si mesmo, movido que está pelo medo da perda de si, chega-se não ao fim da liberdade, mas à

10 AE. 181.

11 Cf. SOUZA, R. T. Fenomenologia e metafenomenologia: substituição e sentido-sobre o tema da "substituição" no pensamento ético de Levinas. In: SOUZA, R.T.; OLIVEIRA, N. F. Fenomenologia hoje - existência, ser e sentido no alvorecer do século XXI. Porto Alegre: EDIPUCRS, 2001. p. 379-414. 
liberdade (traidora de sua idéia?) que nasce de uma outra ordem de razão, chega-se à possibilidade de pensar outramente a liberdade. Como se trocássemos a obsessão do interessamento, pela obsessão do desinteressamento, o que nos dá a chance de pensar a obsessão também antes do princípio do ser. A perseguição pelo outro libera o ser da perseguição do si mesmo. O si-mesmo é a liberdade que resulta dessa perseguição que não termina de começar, que libera inclusive da relação - que em sua idéia não consegue se liberar da liberdade do princípio, da livre escolha, uma vez que pressupõe unidades estabelecidas (a ponto de poderem se relacionar).

[...] o si-mesmo se absolve de si. Liberdade? Liberdade outra que essa da iniciativa. Pela substituição aos outros, o Si-mesmo escapa à relação. No limite da passividade, o Si-mesmo escapa à passividade ou à limitação inevitável que sofrem os termos na relação: na relação incomparável da responsabilidade, o outro não limita mais o mesmo, ele é suportado pelo que limita. É aqui que se mostra a sobredeterminação das categorias ontológicas que lhes transforma em termos éticos. Nesta passividade, a mais passiva, o si-mesmo, eticamente, se libera de todo outro e de $\mathrm{si}^{12}$.

Podemos repensar dessa forma, eticamente, as categorias da subjetividade, da responsabilidade, da liberdade, da ética e do ser. Mudamos o foco de nossa lente, fazendo da ética a ótica ${ }^{13}$. A primeira atitude é já ética, como se víssemos o mundo desde a lente da responsabilidade, sendo ela o comando que determina a ótica, tudo recebendo desde aí um novo sentido. O ser não é recusado - isto seria tolice - mas reabordado a partir de

12 AE. 181-182.

13 Vejamos como a questão aparece na segunda leitura talmúdica de OLT: "Mas eis onde conduz esta integridade lógica da subjetividade: a relação direta com o verdadeiro excluindo o exame prévio de seu teor, de sua idéia - quer dizer, o acolhimento da Revelação - só pode ser a relação com uma pessoa, com outrem. A Torá é dada na Luz de um rosto. A epifania do outro é ipso facto minha responsabilidade com respeito ao outro: a visão do outro é desde já uma obrigação a seu respeito. A ótica direta - sem meditação de nenhuma idéia - só pode se realizar como ética. O conhecimento integral ou Revelação (recepção da Torá) é comportamento ético". QLT. p. 97. Aqui, religião e filosofia se misturam a configurar um discurso híbrido, aliás bastante próprio da judeidade levinasiana, que podemos ver da mesma forma em seus escritos filosóficos. O pensamento de Levinas acaba configurando uma zona de tensão, o excesso do Dizer na estreiteza do Dito, que se reflete sempre no nível da escritura, não importa de que domínio se trate. A divisão que normalmente se faz de seus textos - escritos filosóficos e escritos confessionais - atende a uma exigência acadêmica que muitas vezes atrapalha a leitura do Levinas talmudista - pudor acadêmico - o que acaba por impedir uma interessante recepção filosófica dos estudos ditos confessionais. É preciso abandonar o pudor acadêmico que, em nome de não se sabe mais que espécie de rigor científico, poda, muitas vezes, a fluência do pensamento, sua diversidade de fontes de inspiração. Levinas está muito longe de uma identidade purista de pensamento. Uma leitura conseqüente deve reconhecer em sua filosofia a voz do talmudista, e em seus estudos talmúdicos, a voz do filósofo. Sobre a relação entre o Talmude e a Filosofia no pensamento de Levinas ver CHALIER, C. Levinas et le Talmud. In: CHALIER, C. La trace de l'infini - Emmanuel Levinas et la source hébraïque. Op. cit., p. 235-252. 
exigências não previstas pela abordagem do paradigma identificante. Há uma inversão de ordens e prioridades, conseqüências da ética como filosofia e metafísica primeira. O primeiro movimento do ser não provém de uma escolha, mas de uma inspiração heteronômica, a constituir o próprio psiquismo. Liberdade que libera das exigências de ser, leveza de si. A subjetividade não está na relação inter-subjetiva, como pensávamos em Totalité et infini, mas na sujeição ao outro: o sujeito não se encontra em relação, onde ele já se identificou, mas como suportar do outro, o sujeito é o outro nele. Minha subjetividade é "minha substituição inscrita no meu eu, inscrita como eu. O outro pode substituir a quem quiser, salvo a mim. Provavelmente, é por causa disto que somos numerosos no mundo" ${ }^{14}$. Recebimento da idéia de infinito que a relação já pressupõe. O sujeito se constitui na anarquia da substituição - um-pelo-outro - antes de poder entrar em relação. A substituição é o sujeito fora do ser, alma que nasce antes da chance de sua escolha, dimensão da vida onde não há escolha, gratuidade da responsabilidade e não-gratuidade da liberdade. Devo pagar o preço de ter de aceitar uma responsabilidade sem que possa escolher, para merecer a chance de exercer minha liberdade. A responsabilidade não é o objeto de um saber, mas a constituição prévia deste. Falamos não de um ser que sabe de sua responsabilidade, mas da responsabilidade como psiquismo, vida ou alma, do saber, sabedoria primeira. "Não é possível deixar-se substituir para a substituição, como não é possível deixar-se substituir para a morte" ${ }^{15}$. Como não é possível deixar-se substituir para nascer.

Liberdade que libera do peso de ser para si. Se pensamos a subjetividade pela ótica do saber, onde o caminho para a realização da consciência vai levar à constituição da auto-consciência, substância do ser que é para-si, devemos supor o enorme peso que vai significar esse retorno para a autoconsciência. A subjetividade que retorna é pesada de tanto ser para si. Não significa que a subjetividade está fechada ao encontro, mas que, calcada em sua identidade de substância subjetiva, a cada encontro deve retornar a si, sob o risco de se alienar. Na obsessão do retorno a identidade torna-se um fardo difícil e pesado. A liberdade da transcendência libera desse fardo, liberdade do não retorno a si. A subjetividade não deixa de se identificar por isto, mas não basta a ela sua identidade. Há algo mais obsedante que a necessidade do retorno, algo que a obsessão do enraizamento identitário já pressupõe. No limite, estaremos diante de duas estruturas de justificação do pensamento, uma que precipita o instante do retorno e outra que o adia infinitamente: pensamento que se justifica e se produz na base do retorno do eu a si mesmo e pensamento que se justifica e se produz tendo como base o movimento de adiar esse retorno, onde o eu resolver-se-ia como identidade, ou seja, não teria que responder mais que a si mesmo.

\footnotetext{
14 DVI. 132.

15 VI. 132.
} 
Subjetividade: o si-mesmo liberto do peso de si mesmo e de qualquer outro que tenha nele sua referência de sentido e realidade. Infinitamente leve, na medida em que não necessita suportar-se ontologicamente a si mesma, sem descanso em um jogo perpétuo de espelhos, em recorrentes estruturas autoidentificantes, para sentir-se real; e infinitamente pesada, no sentido de que é capaz de conter infinitamente mais do que pode conter, infinitamente mais do que se poderia pensar - é capaz de suportar o infinito ético, ou seja, a diferença real, o novo ${ }^{16}$.

Neste sentido, liberação do peso da imanência: a subjetividade como identificação do eu a si mesmo - auto-consciência - é uma exigência voltada para dentro, uma complexidade que deve se resolver imanentemente. $\mathrm{Na}$ liberdade da substituição, a exigência está voltada para fora, no movimento da transcendência, onde a complexidade é afetada pelo infinito ético do outro, obsessão do visage, que libera da imanência desejosa de conter o envelhecimento da pele afetada inevitavelmente pela infinitude do tempo. Concebida pelo viés da transcendência, a subjetividade como Questão, suporta essa infinitude, se convertendo em Desejo, aventura de um exílio sem retorno: esvaziamento de si - que não termina de acontecer porque não cessa de começar - e ocupação pelo outro de um território que seria seu e que, não obstante, ele tem que afirmar como sendo seu - ocupação que, por sua vez, também não termina de acontecer porque não cessa de começar. "Identidade em diástase, a coincidência vindo a falhar a ela-mesma"17, a subjetividade é pele que suporta no desgaste do tempo, registro desse desgaste, passividade do envelhecimento. Somente dessa forma é possível pensar uma liberdade convivente com a alteridade do outro. A infinitude deixa de ser o signo da liberdade e passa a significar a anterioridade da responsabilidade: passamos de uma idéia de liberdade incondicional, de onde derivaríamos o conceito de responsabilidade livre - frágil demais para suportar a exigência da ética levinasiana da alteridade - para uma idéia de responsabilidade incondicional, de onde derivamos o conceito de liberdade finita. O que está em jogo é a implicação do querer, uma vez que "na liberdade finita se libera, então, um elemento de liberdade pura que a limitação em seu querer não afeta"18. O querer não garante minha liberdade, mas a condiciona a uma função de meu capricho. Neste caso a responsabilidade se torna inteiramente dependente da boa vontade, não conseguindo fazer ressoar o eco de sua anarquia imemorial. Compreender o ser pela responsabilidade incondicional, ou seja, pelo outramente que ser da substituição, significa abordar o sujeito antes do querer. A responsabilidade, "cuja entrada no ser somente pode se efetuar sem escolha"19, não é uma condição prévia que causaria a liberdade, mas uma inspiração, o sentido que vai tomar o movimento do exercício de minha liberdade.

16 SOUZA, R.T. Fenomenologia e metafenomenologia. Op. cit., p. 394.

17 AE. 182.

18 AE. 197.

19 AE. 183. 


\section{Suportar}

A idéia de suporte pertence ao sentido etimológico da palavra subjetividade. O sujeito sendo o impensado ponto de apoio pelo qual o mundo se apresenta ao pensamento, ponto que não pode partilhar do mesmo modo de apresentação do mundo. Ponto onde "se decide toda marcha do universo" ${ }^{20}$, todo futuro que essa marcha pode vir a realizar depende desse não-lugar. Mesmo que seja na negligência, ainda assim o sujeito não está livre da responsabilidade, que não coube a ele escolher. Não se trata de olhar a forma concreta como a responsabilidade aparece no mundo, e a partir daí procurar a coerência dessa filosofia. O que acontece de bom ou de ruim no mundo não está ao alcance de tirar nenhum pedaço dessa concepção de subjetividade, e, inversamente, pensar o sujeito como responsabilidade e substituição ao outro não alcança o ponto de determinar um resultado convertível em fenômeno mundano. A filosofia não é um "manual" para a transformação do mundo, talvez uma sabedoria que inspira a vida e suas escolhas, jamais determinando. Nesse ponto podemos nos aproximar da convocação da liberdade sartreana, o mundo sendo algo que a todo instante deriva da minha ação nele e sobre ele, o que acontece comigo sendo também algo inteiramente devido a mim mesmo, a idéia interessante e sempre atual de que a liberdade - tanto mais gratuita e fácil quanto mais nos afastamos de uma compreensão profunda e conseqüente da idéia de infinito - não nos autoriza a qualquer que seja a desculpa.

O Si-mesmo é Sub-jectum: está sob o peso do universo - responsável de tudo. A unidade do universo não é o que meu olhar abraça na sua unidade de apercepção; mas o que de todas as partes me incumbe, me mira nos dois sentidos do termo, me acusa, é minha tarefa. [...] Instauração de um ser que não é para si, que é para todos, que é a uma vez ser e desinteresse; o para si significa consciência de si; o para todos significa responsabilidade para com os outros, suporte do universo. Esse modo de responder sem compromisso prévio - responsabilidade para com o outro - é a própria fraternidade humana anterior à liberdade ${ }^{21}$.

Sujeição - sofrer a carga do tempo, do outro, do universo, viver na implicação ética de que tudo me olha e me concerne nesse olhar. Insônia do mundo. A unidade da apercepção não é primeira, assenta sobre uma unidade que não resulta do saber, pois não deixa o sujeito se acomodar para produzir conhecimento. A unidade primeira significa a minha tarefa com relação ao mundo que se apresenta, minha não isenção com respeito a todas as partes que poderão até configurar o sentido de uma unidade de apercepção. Entre o sujeito e o momento em que ele constituiria a unidade de apercepção, unidade do Ser, intervém o vestígio do Infinito, insuficiente para entrar na constituição representativa de um saber, porém suficiente para interromper

20 ADV. 194.

21 AE. 183-184. 
a harmonia da ordem do sujeito na posição do saber e de-por a subjetividade, como se a ordem ética fosse uma intrusão, intermitência do vestígio como a infinitude do Olhar do Outro. A unidade primeira é minha unicidade de sujeito concernido em responsabilidade, o fato de que sou único nessa tarefa, ninguém podendo me substituir na substituição, isto seria uma falsificação de minha assinatura. O caráter extraordinário de uma teoria da subjetividade é que o objeto principal não se encontra no nível da teoria: o que pode ser dito aí não serve para dizer o essencial, a não ser que essa teoria se constitua pela necessidade de desdizer o dito, ou seja, de mostrar em seu desenvolvimento mesmo, na sua manifestação, a diferença entre o dizer e o dito. É no dizer que o sujeito se manifesta, esse nível primeiro de diferença, desapercebido pela diferença ontológica, onde a unidade do universo é a unicidade do sujeito em substituição a todas as partes que, de todos os lados, lhe concernem. A fraternidade humana não é um valor agregado a um sujeito moralizado pelo conceito de liberdade, mas a primeira e mais decisiva ordem, não porque foi a ordem decidida pelo sujeito senão porque vai orientar toda e qualquer livre decisão que ele possa vir a tomar.

\section{Anarquia da linguagem}

A linguagem nos chega como uma forma já perfeitamente constituída, com suas regras e estruturas de definição, suas condições de possibilidade, mas o instante da linguagem é sempre o "instante de um enigma" 22 que não se atualiza nas condições em que a linguagem já se apresenta. Há, portanto, uma problemática coincidência de instantes: o já do enigma coincide com o já das condições formais de possibilidade da linguagem. Esse já do enigma, que é a própria força motriz da linguagem antes de cair numa forma, permanece na linguagem, mas sem a visibilidade de um código decifrador. Tem a ver com a subjetividade, mas não se reduz ao sujeito no ato ou na posse da fala, vai mais longe ainda, sua raiz é mais profunda, permanece anarquia, ou seja, sem dispor do princípio que é o já do primeiro instante da linguagem, o formato ontológico do dito, que, no entanto, na inquietação do instante enigmático que também leva o nome de linguagem, não permanece aí como repouso absoluto. A subjetividade é a intermitência do enigma na linguagem, "acontecimento incessante de sujeição a tudo, de substituição" ${ }^{23}$, momento de exceção do ser, exceção da ontologia.

Não se busca, em toda essa análise, relacionar um ente, que seria o Eu, ao ato de substituir-se, que seria o ser desse ente. A substituição não é um ato, é uma passividade que não se converte em ato, algo mais aquém da alternativa ato-passividade, a exceção que não pode se dobrar às categorias gramaticais como Nome ou Verbo, se não é no Dito que as tematiza. A recorrência, que somente pode se dizer como em si ou como o revés do ser, ou como outramente

2 AE. 185. Nota 1.

23 AE. 185. 
que ser. Ser si mesmo, outramente que ser, desinteressar-se é carregar a miséria e a falta do outro e mesmo a responsabilidade que o outro pode ter de mim; ser si mesmo - condição de refém - é sempre ter um grau de responsabilidade a mais, a responsabilidade pela responsabilidade do outro ${ }^{24}$.

Quando dizemos que a "subjetividade é a substituição ao outro" não estamos atribuindo ao sujeito a "substituição ao outro" como se atribui a um ente uma substância ontológica. Entender a substituição como o ser da subjetividade é exatamente o que esta filosofia não quer. A substituição é o dizer que excetua do sujeito o seu estado ontológico, o enigma da subjetividade, seu segredo mais íntimo, sua essência indizível. A responsabilidade é um estado de desacomodação incessante, sem trégua, sem pausa para repousar, o aquém da condição: "sofrimento do outro, minha piedade pelo seu sofrimento, sua dor por causa de minha piedade, minha dor por causa de sua dor, etc; isto se detém em mim" 25 . Não há simetria nesta relação, a responsabilidade desconhece os signos do acordo mútuo, onde o interesse das partes já está em jogo. A subjetividade é a capacidade de sofrer porque o outro sofre, o que vai gerar um movimento sem retorno e sem fim, pois implica no desejo do que não se pode desejar para ninguém, desejo de abrigar a dor do outro e de estancar no próprio corpo o sangue e a lágrima que escorrem do corpo do outro. Mistério e milagre do amor.

Ter-o-outro-em-sua-pele, como se o primeiro sentimento que eu pudesse dizer de mim mesmo coincidisse com o sentimento da pele do outro. A identidade coincide com a alteridade no acontecimento do outramente que ser, de modo que nunca posso retornar à mesmidade de um Eu identificado a si mesmo. No meu dizer de mim, permaneço aquém de mim. No meu dizer de mim se manifesta a alteridade do outro: "Eu é um outro - [...]. É preciso falar aqui de expiação, como reunindo identidade e alteridade" 26 . A identidade é uma alteração, fissuras da substância, o escorrer de um estado a outro, numa recorrência que não encontra fim, onde nada mais sólido do que a suportabilidade do outro se possa pensar. Dizer eu é dizer sim ao outro porque é já responder em presença dele. Dizer eu é apresentar ao mundo a ordem da paz, o que não significa nenhuma garantia de que o mundo vai fazer valer essa ordem. Mesmo porque não se trata, para o lado do mundo, de assumir a função de instaurar a paz, de resto, um exercício cujo objetivo permanece fora do território de alcance do poder que ele comanda, sem desprezar a nobreza de atos políticos em favor da paz. A paz é o vestígio da mais remota arqueologia do ser humano, tão presente na linguagem quanto insondável por ela mesma. Tão presente na linguagem quanto confere a própria possibilidade desta, que não nasce senão de um voto de confiança em direção à demasia obsedante do outro, não de um acordo de paz, onde

\footnotetext{
24 AE. 185-186.

25 AE. 186. Nota 1.

26 AE. 187.
} 
os interesses já se apresentaram como princípio mediador, mas pelo sim incondicional e traumático, sim sem restrições, sem exame prévio, sem condições de se dizer, pois que é dizer antes das condições, acolhimento primeiro mediante o qual meu nome me significa, "como se a unidade e a unicidade do Eu fosse já a tomada sobre si mesmo da gravidade do outro"27, coisa que não pode depender de um exame prévio, simplesmente porque obedece a um outro plano metafísico, a ética. A acolhida do outro é imediata porque é só ela quem pode fundar toda e qualquer estrutura de mediação, como, por exemplo, a ordem do saber. O sujeito do conhecimento é sempre mais novo que o sujeito do acolhimento. Assumir sua identidade tem um sentido preciso, dizer sim à primazia dos outros. Estar a serviço dos outros. Longe de parecer uma apologia da relação servil, não seríamos tão idiotas nem ingênuos. Nenhuma hierarquia nasceu ainda, não se trata de servir no exercício de um papel definido numa organização já cultural do mundo, algo que, de resto, só serve a leis instituídas para um já determinado funcionamento do mundo. Neste caso, alguém está cumprindo com o seu dever, movido pela função que cabe àquele quando encarna aquele papel. Nesta ordem, o outro se encontra soterrado sobre as camadas das representações sociais. O serviço de que trata a ética levinasiana da alteridade é o acolhimento incondicional, aliança imemorial e anárquica da paz, compromisso com uma promessa que não dá a quem promete qualquer garantia de retorno. Esta incondicionalidade do acolhimento infinito é a subjetividade.

\section{A hospitalidade do refém}

A palavra otage (refém) - freqüentemente presente no vocabulário levinasiano, e sobretudo quando se trata de discorrer sobre o tema da subjetividade - nos conduz a uma interessante e reveladora etimologia. Trata-se do parentesco semântico das palavras otage, hôte, hospitalité refém, hóspede e hospedeiro, hospitalidade. O português dificulta o acesso a esse parentesco, mas ele faz bastante sentido para compreender a lógica levinasiana da substituição. A palavra hôte significa duas coisas que nós distinguimos como hospedeiro - "dono da hospedaria" - e hóspede - o que deverá receber seus serviços. Como entender? O hospedeiro é alguém cuja vida consiste em servir o hóspede, que está sempre prestes a aparecer. Sua hospedaria, sua casa, deve estar, portanto, sempre em prontidão para que o hóspede chegue e se instale, se acomode. A casa do hospedeiro não pertence bem a ele, é primeiro do hóspede. O que nos leva à idéia de que o hospedeiro é aquele que já tem em sua casa - chez soi - um hóspede, ele é o chez moi do hóspede, sua razão de ser é ser-para-o-hóspede, no ponto em que a identidade do hospedeiro só pode ser compreendida pela alteridade do hóspede, sendo a alteridade do hóspede a possibilidade de que o hospedeiro possa dizer de si. "O Si mesmo (Soi) é o fato mesmo de se expor, sob o

$27 \mathrm{AE} .187$. 
acusativo não assumível onde o $\mathrm{Eu}$ (Moi) suporta os outros, no inverso da certeza do Eu (Moi) se reunindo a si mesmo na liberdade"28. Estou sempre antes da minha liberdade, ou ainda, se quando penso já sou eu em minha liberdade, nunca chego a trazer ao presente de meu pensamento a minha mais remota origem, inspirado que fui desde lá pela idéia do infinito.

A idéia do refém na imagem do hospedeiro que também é hóspede é uma boa metáfora da substituição, mas talvez não tão concreta quanto a da maternidade, embora tão elucidativa quanto. Na maternidade, a mãe é refém de seu filho: a gravidez, onde um corpo vira casa de outro corpo, torna-se a própria ilustração da subjetividade. $\mathrm{Na}$ gravidez a mãe diz a substituição no nível mais concreto da linguagem, o da sensibilidade - a mãe reúne identidade e alteridade em seu próprio corpo. Todas as figuras levinasianas da subjetividade ganham visibilidade no corpo da mulher grávida, corpo, por excelência, de hospedeira. A idéia de que a responsabilidade é o desejo de transferir para o seu corpo a dor que o outro sente realiza-se, no sentido mais absoluto da palavra, na maternidade, abandona o estatuto de idéia e aparece como fenômeno do mundo. A dor do filho dói no corpo da mãe, não como desejo metafísico, mas como concretude sentida na pele. Tudo o que se fala de subjetividade nessa filosofia encontra aí o seu protótipo mais arquetípico, a maternidade. A mãe realiza a coincidência, tão difícil de caber na lógica da representação, entre identidade e alteridade, numa relação que não é de uma vez por todas dialética, pois a alienação que a alteridade causa na identidade, neste caso, configura algo diferente que na lógica da consciência alienada de Hegel. Significa a ordem do exílio de si em si mesmo, outra idéia de identidade, não coincidência que se traduz como precedência do outro, responsabilidade primeira por ele. Prontidão do eis-me aqui.

O tema da substituição, ao desenhar uma estrutura que precede o nível em que a subjetividade era entendida como relação ao outro - e ela não deixa totalmente de ser entendida como tal - amplia o contexto em que pensamos a linguagem como transcendência da comunicação: "a substituição é uma comunicação de um ao Outro e de Outro ao um sem que as duas relações tenham um mesmo sentido"29, ou seja, sem que tenhamos aí propriamente uma relação, no sentido em que normalmente compreendemos esta palavra, a saber, como "trocas" ocorridas num mesmo nível, como lugar de alcance mútuo de duas partes distintas e abordáveis na relação, como reciprocidade. Se não há reciprocidade, se o sentido da ida não encontra o sentido da volta, não temos propriamente uma relação. Quando falamos em relação de comunicação não estamos cumprindo com a expectativa que essa noção, tão cara às filosofias do diálogo, cria ao ser ouvida. A razão que comanda a comunicação não está propriamente atenta

28 AE. 188.

29 AE. 188. Nota 1. 
ao conjunto de informações que estão sendo trocadas, há algo que excede esse nível, algo que é dito sem que chegue a corresponder a uma verdade desvelada pelas palavras, algo que corresponderia a uma expectativa que o sujeito falante supõe que haja na presença de quem a ele se dirige - mas supõe sem saber que está supondo, como se a inquietação da fala dissesse algo além de uma mera preocupação com a informação -, de resto, uma suposição condenada a não poder se confirmar de nenhuma forma, por um lado pela não consciência do sujeito que supõe e, por outro, no que diz respeito ao interlocutor, porque não há nenhum signo que possa ser desvelado neste sentido. A comunicação cria essa zona de excesso onde uma outra razão que não a do conhecimento atua. "A relação com o outro precede a auto-afecção da certeza a qual se procura sempre reconduzir a comunicação" ${ }^{30}$. Isto porque uma hétero-afecção ${ }^{31}$ atua primeiro, não num sentido cronológico, mas desde uma outra ordem de racionalidade. Razão que não dá garantia, antes mantém o falante sob suspeita, como se ele não comandasse a própria fala. A comunicação só é possível no equívoco, "como vida perigosa, como um belo risco a correr" 32 . Dessa maneira também falamos com Levinas a respeito da relação erótica, do amor como o equívoco por excelência.

\section{Ética da substituição}

A ética da substituição é a proximidade que significa a relação "sem a mediação do logos" ${ }^{33}$, portanto, sem possibilidade de discernir sobre o que do que se aproxima, e finalmente, sem que a consciência da relação possa chegar a si mesma. "Proximidade e não verdade sobre a proximidade; não a certeza sobre a presença de Outrem, mas responsabilidade por ele sem a deliberação da compulsão de verdades onde nascem os engajamentos, sem certeza" ${ }^{34}$. A substituição não é um engajamento, uma tomada de posição que pressuporia uma concessão feita por um sujeito já livre e consciente de suas ações no mundo. Significa uma situação anterior, onde o próximo já está implicado em mim, onde já estou afetado pela idéia do infinito, sem que pudesse ainda nascer para o conceito. A substituição é a obsessão do infinito no finito. A consciência reflexiva não reflete o nível profundo de sua própria afetação, não reflete o desejo do infinito que é sua zona cega. Mas a reflexão respira o indeterminado absoluto da questão - vem daí o alimento do fogo que inspira o pensamento. A ética da substituição é a consciência excedida pela paixão do infinito - a questão do pensamento. Antes do ser, aquém do princípio, anarquia imemorial do mundo.

30 AE. 189.

31 Cf. AE. 193.

$32 \mathrm{AE} .190$.

33 AE. 193.

34 AE. 191. 


\section{Referências}

BLANCHOT, M. A conversa infinita - a palavra plural. São Paulo: Escuta, 2001.

CHALIER, C. Pour une morale au-dela du savoir - Kant et Levinas. Paris: Albin Michel, 1998.

. La trace del'infini-Emmanuel Levinasetla source hébraïque. Paris : Cerf, 2002.

LEVINAS, E. Autrement qu'être ou au-delà de l'essence. Paris: Kluwer Academic, 2001. . De Deus que vem à idéia. Petrópolis: Vozes, 2002.

. Quatroleituras talmúdicas. São Paulo: Perspectiva, 2003.

. Au-delà du verset, lectures et discours talmudiques. Paris: Les Éditions du Minuit, 2002.

PETROSINO, S.; ROLLAND, J. La vérité nomade - introduction à Emmanuel Lévinas. Paris: La découverte, 1984.

SOUZA, R. T. de; OLIVEIRA, N. F. de. (Orgs.). Fenomenologia hoje - existência, ser e sentido no alvorecer do século XXI. Porto Alegre: EDIPUCRS, 2001. 